\title{
Synthesis, Characterization, Structural Exploration and Quantum Chemical Calculations of (E)-8-(1-((4-aminobenzyl)imino)ethyl)-7- hydroxy-4-methyl-coumarin
}

\author{
CHETHAN PRATHAP K. N. ${ }^{1 *}$, NIRANJANA S..$^{2}$ and LOKANATH N. K. ${ }^{2}$ \\ 'Department of Physics, University College of Science, Tumkur University, Tumakuru-572103, India. \\ ${ }^{2}$ Department of Studies in Physics, Manasagangotri, University of Mysore, Mysuru-570006, India. \\ ${ }^{*}$ Corresponding author E-mail: cpforphysics@ gmail.com \\ http://dx.doi.org/10.13005/ojc/370231
}

(Received: March 19, 2021; Accepted: April 20, 2021)

\begin{abstract}
Coumarin derivatives are one of the very important compounds of high biological interest. A

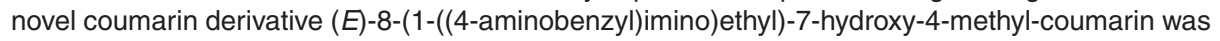
synthesized using substituted acetyl coumarin and 4-aminobenzylamine. Following the detailed spectroscopic characterization, the structure of the compound was confirmed using XRD studies. The novel coumarin derivative crystallizes in monoclinic crystal system in P21/c space group and displays diverse intermolecular interactions. One-dimensional array along b-axis and $\mathrm{R}^{2}(18)$ supramolecular architectures are" 0 formed mediated by $\mathrm{N} 24-\mathrm{H} 24 \ldots \mathrm{O} 1$ and $\mathrm{C} 17-\mathrm{H} 17 \ldots \mathrm{O} 10$ hydrogen bonds respectively. Hirshfeld surface analysis quantified that $\mathrm{H} \ldots \mathrm{H}, \mathrm{C} \ldots \mathrm{H}$ and $\mathrm{O} \ldots \mathrm{H}$ contacts are the major contributors to the crystal structure with a contribution of $42.9 \%, 32.7 \%$ and $20.1 \%$ of total interactions respectively. Further, structural optimization was carried out using quantum chemical DFT calculations that displayed high correlation with XRD structure. The electronic absorption spectrum from TDDFT calculations is matching well with the results of UV-visible spectrum.
\end{abstract}

Keywords: Coumarin derivatives, XRD, Hirshfeld surface analysis, Density functional theory, UV-visible spectrum.

\section{INTRODUCTION}

Coumarin derivatives have been used extensively in several pharmaceuticals due to their diverse biological properties. They have been observed to possess antitumor, antituberculosis, antioxidant, anti-inflammatory, antiviral, and antimicrobial activities ${ }^{1-6}$. Several coumarin derivatives have displayed activities such as inhibition of HIV-1 replication with anti-HIV activity and anti-cancer and anti-tumor activities ${ }^{7-14}$. Coumarin derivatives are used in agricultural sector as potential seed protectants as well as pesticides and rodenticides ${ }^{15-17}$. Coumarin derivatives have shown high fluorescent properties that make them suitable candidates for bioimaging and in-cell fluorescent applications ${ }^{18-19}$. Studies have also shown that several coumarin derivatives act as enzymatic inhibitory agents in neurodegenerative diseases such as Alzheimer disease and hence are being employed in its treatment modalities. ${ }^{20-22}$

This is an Open Access article licensed under a Creative Commons license: Attribution 4.0 International (CC- BY). Published by Oriental Scientific Publishing Company @ 2018 
These various physical and biological properties inspired us to synthesize a novel coumarin derivative: (E)-8-(1-((4-aminobenzyl)imino)ethyl)-7hydroxy-4-methyl-coumarin. Characterization was carried out using various spectroscopic technique. The optical properties were studied using UV-Visible spectroscopy. The final three-dimensional structure of the compound was obtained using XRD method. Intermolecular interactions and their contribution to crystal structure were studied. Energy frameworks analysis and lattice energy computation were also performed. DFT calculations were employed in optimization of the structure. Further, HOMO-LUMO that control most of the global and local, physical and chemical properties were also studied.

\section{MATERIALS AND METHODS}

\section{Instrumentation}

All the reagents used in the synthesis of the novel coumarin derivative were obtained from Sigma-Aldrich co., that were of very high purity and hence used directly. The completion of the reaction was surveilled by means of TLC using silica- 60 coated plates and fluorescent indicator of $256 \mathrm{~nm}$ ultra-violet light. Proton and ${ }^{13} \mathrm{C}$ NMR spectral data were collected with "Agilent-NMR" spectrometer and the chemical shifts have been reported in terms of ppm. The FTIR spectrum data were collected using "Perkin Elmer 100" and wave numbers have been reported in per centimeters. The recording of UV-Visible spectroscopic investigation was done with the help of "Perkin Elmer $\lambda-35$ " with acetonitrile as the solvent.

Synthesis of (E)-8-(1-((4-aminobenzyl)imino) ethyl)-7-hydroxy-4-methyl-coumarin

A novel coumarin derivative was obtained from the reaction between 7-hydroxy-4methylcoumarin and 4-aminobenzylamine in absolute ethanol. $5 \mathrm{mmol}$ solution of 4-aminobenzoylamine in $10 \mathrm{~mL}$ of absolute ethyl alcohol was added slowly to the boiling solution of $5 \mathrm{mmol}$ of 7-hydroxy-4methylcoumarin in absolute ethyl alcohol $(25 \mathrm{~mL})$ and was refluxed at $78^{\circ} \mathrm{C}$ for five hours and was cooled overnight. The precipitated product was filtered and dried under reduced pressure. The reaction pathway is represented in the scheme shown in Figure 1.

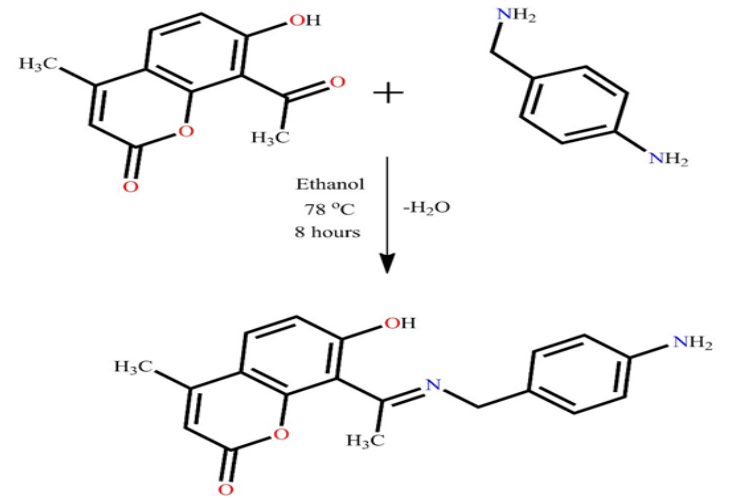

Fig. 1. Schematic representation of reaction pathway

\section{Spectroscopic analysis}

The compound was characterized using NMR spectroscopy. Both ${ }^{1} \mathrm{H}$ and ${ }^{13} \mathrm{C}$ NMR spectroscopic investigations were undertaken using deuterated DMSO as solvent with the frequency of $400 \mathrm{MHz}$ and $100 \mathrm{MHz}$ respectively. The NMR spectra is given in Fig. 2. The chemical shifts corresponding to the peaks of Proton NMR were observed at: $\delta 7.36(\mathrm{~d}, 1 \mathrm{H}), \delta$ $7.06(\mathrm{~d}, 2 \mathrm{H}), \delta 6.67(\mathrm{~d}, 2 \mathrm{H}), \delta 6.43(\mathrm{~d}, 1 \mathrm{H}), \delta 5.81(\mathrm{~s}$, $1 \mathrm{H}), \delta 4.51(\mathrm{~s}, 2 \mathrm{H}), \delta 2.38(\mathrm{~s}, 3 \mathrm{H}), \delta 2.35(\mathrm{~s}, 3 \mathrm{H}) \mathrm{ppm}$ and the chemical shifts corresponding to the peaks of Carbon $-{ }^{13}$ NMR were observed at 166.4, 159.8, $159.5,154.5,150.0,140.3,132.1,130.5,129.3$, $115.9,114.5,112.2,52.3,20.8$ ppm.

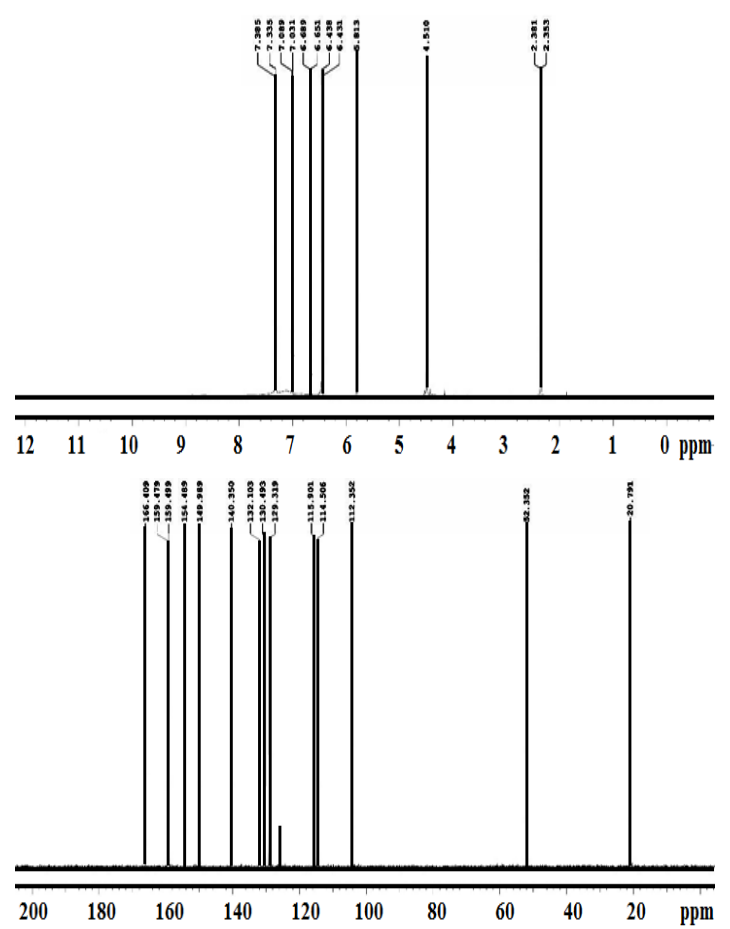

Fig. 2. ${ }^{1} \mathrm{H}$ and ${ }^{13} \mathrm{C}$ NMR of the compound 
The peaks of FTIR spectrum correspond to different molecular vibrations. An absorption peak at $3570 \mathrm{~cm}^{-1}$ corresponds to $\mathrm{N}-\mathrm{H}$ stretching and several peaks in the range of $3000 \mathrm{~cm}^{-1}$ to 3020 $\mathrm{cm}^{-1}$ correspond to various $\mathrm{C}-\mathrm{H}$ stretching. Notable absorption peaks at $2510 \mathrm{~cm}^{-1}$ and $1840 \mathrm{~cm}^{-1}$ are associated with $\mathrm{O}-\mathrm{H}$ and $\mathrm{C}=\mathrm{O}$ stretching vibrations. The finger print region contains several absorption peaks under $1500 \mathrm{~cm}^{-1}$ corresponding to vibrations involving several bonds. The experimentally measured FTIR spectrum is given in Figure 3 .

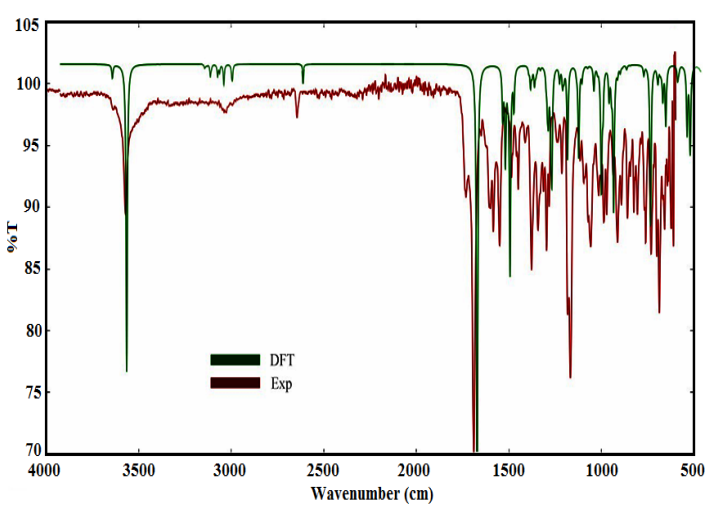

Fig. 3. Experimental and theoretical FTIR spectra of the compound

\section{Single crystal XRD studies}

$X$-Ray diffraction studies were carried out using a crystal of size $0.2 \times 0.25 \times 0.35 \mathrm{~mm}^{3}$. Intensity data were recorded on a "Rigaku XtaLAB mini" at a temperature of $293 \mathrm{~K}$ with MoK $\alpha$ target that produces X-rays of wavelength $0.71073 \AA$. The $\phi$ angular settings were kept $\left(0^{\circ}\right.$ to $\left.90^{\circ}\right)$ with $0.5^{\circ}$ scan width and three seconds of exposure time. The data were collected with a distance of $50 \mathrm{~mm}$ between the sample and the detector. The data integration was carried out using Crystal $\mathrm{Clear}^{23}$ software. The initial cell measurement revealed that the title molecule belongs to $P 21 /$ cspace group under monoclinic crystal system. Direct methods were employed to solve the crystal and molecular structure. The structure solution and refinement were done using SHELXS and SHELXL software respectively ${ }^{24-25}$. The first difference Fourier map revealed peaks corresponding to all carbon, oxygen and nitrogen atoms that were anisotropically refined before fixing hydrogen atoms at acceptable geometrical position with appropriate riding model. With the progress of refinement as the residual factor converged to 0.0704 and the difference Fourier map peaks did not retain any chemical significance. The crystal structure parameters, refinement data and results are enlisted in Table 1. PLATON ${ }^{26}$ program was used for calculating all the geometrical parameters and MERCURY ${ }^{27}$ software was used to obtain the crystallographic diagrams.

\section{Hirshfeld surface analysis}

The visual interface provided by the Hirshfeld surface analysis helps in the effective study of molecular shapes in crystalline environment and various intermolecular interactions that contribute to the crystal stability. The $d_{\text {norm }}$ mapped Hirshfeld surface was generated to explore and quantify the diverse intermolecular interactions present in the title compound. Morphology of Hirshfeld surface was visualized by color coding interior $\left(\mathrm{d}_{\mathrm{i}}\right.$ ) or exterior $\left(d_{\mathrm{e}}\right)$ distances of the surface to the nearest atoms. The Hirshfeld surface mapped with normalized distance were generated with a color coding of blue for negative values $(-0.144 \mathrm{au})$ and red for positive values $(1.38 \mathrm{au})$ respectively. The fingerprint plots with exterior and interior distances that range from $0.4 \AA$ to $2.6 \AA$ were also generated. Further, the calculations of intermolecular interaction energies, lattice energy and energy frameworks were also carried out. All the calculations were performed using Crystal Explorer v-3.028-30.

Table 1: Crystal structure and refinement details

\begin{tabular}{|c|c|}
\hline Parameter & Value \\
\hline CCDC deposit No. & 2068030 \\
\hline Formula & $\mathrm{C}_{19} \mathrm{H}_{18} \mathrm{~N}_{2} \mathrm{O}_{3}$ \\
\hline Molecular mass & 322.35 \\
\hline Radiation & MoK $\alpha$ \\
\hline Wavelength & 0.71073 \\
\hline Crystal family & Monoclinic \\
\hline S - group & $P 21 / c$ \\
\hline a $(\AA)$ & $10.8724(1)$ \\
\hline b $(\AA)$ & $5.6298(8)$ \\
\hline$c(\AA)$ & $26.0210(4)$ \\
\hline$\beta\left(^{\circ}\right)$ & $97.989(2)$ \\
\hline Size (Å3) & $1580.3(4)$ \\
\hline Z & 4 \\
\hline Absorption coeff. (mm-1) & 0.093 \\
\hline $\mathrm{F}_{000}$ & 680 \\
\hline Crystal dimension (mm3) & $0.2 \times 0.25 \times 0.35$ \\
\hline Data collection range: $2 \theta\left(^{\circ}\right)$ & 2.289 to 32.333 \\
\hline Index ranges & $\begin{array}{l}-14 \leq \mathrm{h} \leq 15 ;-7 \leq \\
\mathrm{k} \leq 4 ;-12 \leq \mathrm{I} \leq 36\end{array}$ \\
\hline Spots collected/unique/parameters & $4942 / 2431 / 219$ \\
\hline Absorption corr. method & Multi scan \\
\hline Goof on $\mathrm{F}^{2}$ & 1.021 \\
\hline $\mathrm{R}_{1}, \mathrm{wR}_{2}$ indexes $[\mathrm{I}>=2 \sigma(\mathrm{I})]$ & $0.0704,0.1518$ \\
\hline $\mathrm{R}_{1}, \mathrm{wR}_{2}$ indexes [all] & $0.1515,0.1994$ \\
\hline Extreme diff. peak and hole $\left(e \AA^{-3}\right)$ & 0.364 and -0.249 \\
\hline
\end{tabular}




\section{DFT calculations}

The electron wave functions generated using the density function of any molecule can be used to compute the physical and chemical properties of the molecule. Such calculations play a very significant role in theoretical investigation of the molecular properties. Gas phase optimization of the structure of the title compound was performed with density functional theory. The calculations were performed using B3LYP at $6-311 \mathrm{G}+(\mathrm{d}, \mathrm{p})^{31-}$ 33 basis functions. Transitions among various molecular orbitals control the optical properties of the compound. Optical absorption spectrum was generated by studying electronic transitions with the help of time dependent DFT calculations ${ }^{34}$. The calculations were done using same set of functionals and basis set for lowest 15 singlet-singlet transitions. HOMO-LUMO, corresponding energy gap, and the associated local and global parameters were estimated $^{35}$. The electrostatic potential map of the molecule (MEP) is an effective tool to visualize the possible reactive sites of the molecule. The MEP can be plotted by computing the effective electrostatic potential around the molecule using quantum chemical calculations. All the quantum chemical computations were performed using "Gaussian 09" [36]. Results of the calculations were analyzed and visualized using GaussView ${ }^{37}$.

\section{RESULTS AND DISCUSSIONS}

\section{Optical absorption studies}

Transitions among various $\sigma$ and $\pi$ states of the molecule results in the absorption in the visible to ultraviolet region of the electromagnetic spectrum. This optical absorbance of the title molecule was studied using UV-visible spectroscopy. The experiment was carried out using solution of the title compound in acetonitrile with $25 \mu \mathrm{g} / \mathrm{mL}$ concentration. The absorbance was investigated in the wavelength range from $200 \mathrm{~nm}$ to $700 \mathrm{~nm}$. The compound showed no absorbance for wavelength more than $400 \mathrm{~nm}$; however, it displayed a slightly broad absorbance peak from $300 \mathrm{~nm}$ to $280 \mathrm{~nm}$. Below $275 \mathrm{~nm}$, the absorbance decreased rapidly and approached zero by $240 \mathrm{~nm}$. The broad peak can be attributed to be due to contribution from several transitions with a nearly equal energy difference. The experimentally measured UV-visible absorbance spectrum is shown in Fig. 4 using green colored curve.

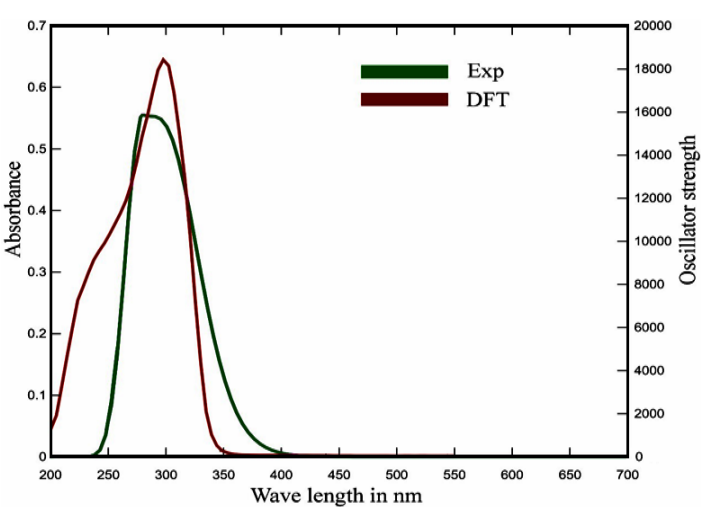

Fig. 4. Experimental (green) and calculated (red) UV-Visible spectrum

\section{X-ray diffraction studies}

$X$-ray diffraction is the ultimate tool in threedimensional structure determination that gives the final confirmation of the molecular structure. The structure of the title compound was determined using single crystal X-ray diffraction studies. The title molecule contains an eleven atom coumarin moiety substituted with a methyl group at position 7 and a benzene ring with substituted amino group at position 4 connected through an imine bond linkage. The coumarin moiety is highly planar with a highest deviation of $0.017 \AA$ from the mean plane for C4 atom. The terminal benzene ring is twisted with respect to the plane of coumarin moiety with a dihedral angle of $69.41(8)^{\circ}$. The title compound is in E-conformation about imine bond as indicated by the C14-N16C17-C18 torsion angle of $179.4(2)^{\circ}$. The ORTEP diagram not only provides the molecular structure, but also provides the details of thermal vibrations of every atom in the molecule and is given in Fig. 5. Structural parameters such as bond length, bond angle and torsion angles were found to be in excellent agreement with the similar structures as well as with those values obtained from theoretical calculations. Table 2 provides a list of selected geometrical parameters of the novel coumarin derivative.

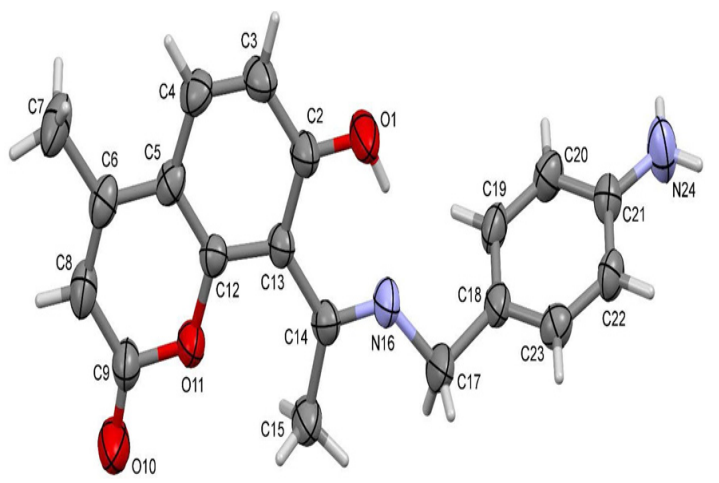

Fig. 5. ORTEP of the title compound. 
Table 2: Selected geometrical parameters of the molecule

\begin{tabular}{|c|c|c|c|c|c|}
\hline & & \multicolumn{3}{|c|}{$X R D$} & $\mathrm{DFT}$ \\
\hline \multicolumn{6}{|c|}{ Selected bond lengths $(\AA ̊)$} \\
\hline & C9 & 010 & $1.211(3$ & & 1.2095 \\
\hline & C9 & 011 & $1.387(3$ & & 1.4058 \\
\hline & 011 & $\mathrm{C} 12$ & $1.371(3$ & & 1.3601 \\
\hline & C14 & N16 & $1.303(3$ & & 1.2963 \\
\hline & N16 & C17 & $1.467(3$ & & 1.4636 \\
\hline & $\mathrm{C} 21$ & N24 & $1.370(3$ & & 1.3965 \\
\hline & $\mathrm{C} 2$ & $\mathrm{C} 13$ & $1.443(2$ & & 1.4341 \\
\hline & C17 & $\mathrm{C} 18$ & $1.502(3$ & & 1.5139 \\
\hline \multicolumn{6}{|c|}{$\begin{array}{l}\text { Correlation coefficient: } \\
\text { Selected bond angles }\left({ }^{\circ}\right)\end{array}$} \\
\hline & C8 & $\mathrm{C9}$ & 010 & 127.76 & $128.2(2)$ \\
\hline & $\mathrm{C} 8$ & $\mathrm{Cg}$ & 011 & 115.45 & $116.2(2)$ \\
\hline & 010 & $\mathrm{Cg}$ & 011 & 116.8 & $115.6(2)$ \\
\hline & $\mathrm{C} 13$ & C14 & N16 & 115.92 & $116.82(19)$ \\
\hline & $\mathrm{C} 15$ & $\mathrm{C} 14$ & N16 & 122.31 & $119.0(2)$ \\
\hline & C14 & N16 & $\mathrm{C} 17$ & 123.4 & $126.2(2)$ \\
\hline & N16 & $\mathrm{C} 17$ & $\mathrm{C} 18$ & 111.44 & $110.7(2)$ \\
\hline & $\mathrm{C} 20$ & $\mathrm{C} 21$ & $\mathrm{C} 22$ & 118.25 & $118.01(19)$ \\
\hline & $\mathrm{C} 20$ & $\mathrm{C} 21$ & N24 & 120.73 & 121.2(2) \\
\hline & $\mathrm{C} 17$ & $\mathrm{C} 18$ & C19 & 121.09 & $121.7(2)$ \\
\hline \multicolumn{6}{|c|}{$\begin{array}{l}\text { Correlation coefficient: } \\
\text { Selected torsion angles }\left(^{\circ}\right)\end{array}$} \\
\hline C14 & N16 & $\mathrm{C} 17$ & C18 & 177.13 & $150.2(2)$ \\
\hline N16 & C17 & C18 & C19 & -53.28 & $-55.8(3)$ \\
\hline N16 & C17 & $\mathrm{C} 18$ & $\mathrm{C} 23$ & 128.16 & $128.7(2)$ \\
\hline C17 & $\mathrm{C} 18$ & C19 & $\mathrm{C} 20$ & -178.72 & $-174.9(2)$ \\
\hline $\mathrm{C} 8$ & $\mathrm{C9}$ & 011 & $\mathrm{C} 12$ & 0.24 & $0.4(3)$ \\
\hline O10 & $\mathrm{C9}$ & 011 & $\mathrm{C} 12$ & -179.83 & $-179.8(2)$ \\
\hline C9 & 011 & $\mathrm{C} 12$ & C5 & -0.72 & $-0.4(3)$ \\
\hline C9 & O11 & C12 & C13 & 179.9 & $179.9(2)$ \\
\hline 01 & $\mathrm{C} 2$ & $\mathrm{C} 13$ & $\mathrm{C} 12$ & -177.96 & $-178.8(2)$ \\
\hline 01 & $\mathrm{C} 2$ & $\mathrm{C} 13$ & C14 & 2.31 & $0.0(3)$ \\
\hline \multicolumn{5}{|c|}{ Correlation coefficient: } & 0.9998 \\
\hline
\end{tabular}

The compound exhibits two intermolecular hydrogen bonds of N24-H24B...O1 and C17H17A...O10 and one O1-H1...N16 intra molecular hydrogen bond. The $\mathrm{C} 17-\mathrm{H} 17 \mathrm{~A}$...O10 hydrogen bond with donor to accepter distance of 3.355(4) $\AA$ results in the formation of $R^{2}(18)$ type supramolecular synthon. Further, an array of molecules is formed along b-axis through the N24-H24B...O1 hydrogen bonds as shown in Fig. 4. These intermolecular hydrogen bonds enrich the molecular interactions that contribute highly to the stability of crystal structure. Details of the hydrogen bond geometry are given in Table 3. The novel coumarin derivative also exhibits a $\mathrm{C}-\mathrm{H}$.... Cg interaction with the center of gravity of terminal benzene ring as shown in Fig. 6. Further, the terminal benzene rings have shown a weak $\mathrm{Cg}-\mathrm{Cg}$ interaction with a mean distance of $4.7994 \AA$ between the centers of gravity of the two rings along $-x, 1 / 2+y, 1 / 2-z$ symmetry direction.

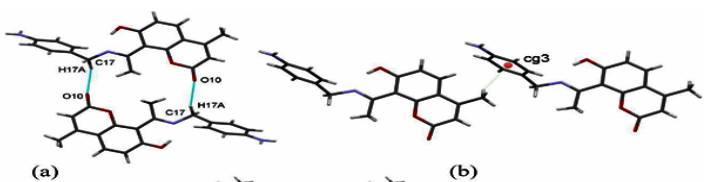

(a)

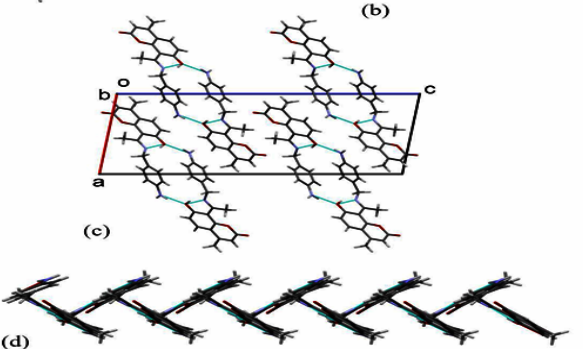

Fig. 6. (a) hydrogen bonds and supramolecular architecture (b) C-H...Cg interaction geometry (c) packing as viewed along b-axis and (d) 1D chain formation down b-axis in the title molecule

Table 3: Various interactions observed in the title compound

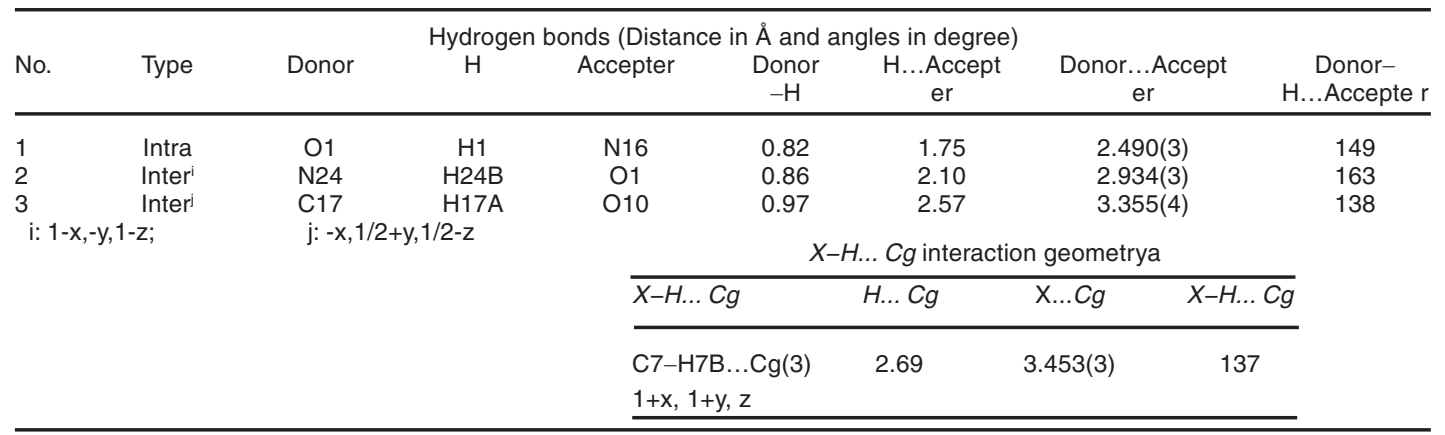

\section{Hirshfeld surface analysis}

The Hirshfeld surface analysis helps in understanding the molecular shape in the crystalline environment and also in quantifying various intermolecular interactions observed in the crystal structure. Hirshfeld surface analysis was carried out and the finger print plots, that are a graphical representation of intermolecular interactions were also plotted. Fig. 7 (a) shows the dnorm mapped Hirshfeld surface where the red colored patches represent the high interaction regions that are associated with intermolecular hydrogen bonds. It 
was observed that the $\mathrm{H}$...H contacts are the major contributors to the Hirshfeld surface with a contribution of $42.9 \%$ of the total intermolecular interactions. C...H followed by $\mathrm{O} \ldots \mathrm{H}$ interactions were observed to contribute $32.7 \%$ and $20.1 \%$ of the total intermolecular interactions indicating their significant role in crystal structure stability. Fig. 7 shows the fingerprint plots generated for different intermolecular interactions along with their contributions.

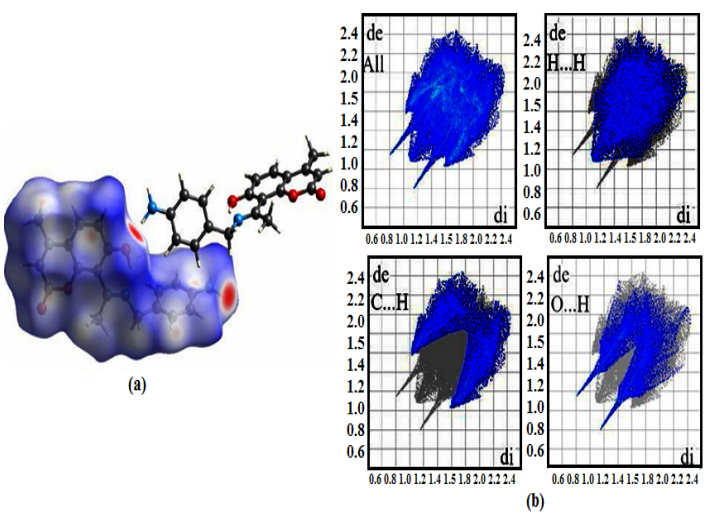

Fig. 7. $d_{\text {norm }}$ mapped Hirshfeld surface and Finger print plots

Along with the quantification of percentage of contribution from various intermolecular interactions to the crystal structure, interaction energies between different molecular pairs were also calculated. The Fig. 8 shows selected, highly contributing molecular pairs with very high interaction energies. The strongest intermolecular interaction was observed to be with the molecule present at symmetry position $(x, y$, z) with a mean distance of $5.63 \AA$ and has a total interaction energy $-37.5 \mathrm{~kJ} / \mathrm{mol}$. The next highest interaction energy was observed with the molecular pair at symmetry position $(-x,-y,-z)$ with distance of $6.17 \AA$ and total interaction energy of $-37.0 \mathrm{~kJ} /$ mol. These two molecules are described in red and blue colors respectively in Fig. 8. The two molecules described in yellow and purple colors with a distance of $10.73 \AA$ and $7.92 \AA$ have total interaction energies of $-25.7 \mathrm{~kJ} / \mathrm{mol}$ and $-24.7 \mathrm{~kJ} / \mathrm{mol}$ respectively. The total interaction energy has contributions from various energy factors such as electronic, polarization, dispersive and repulsive energies. Individual energy component and the total interaction energy are listed in Table 4. The energy frameworks consist of tubular representation along with the crystal packing with diameter of the tubes being proportional to the intermolecular interaction energy along that direction. Hence the energy frameworks enable us to understand the strength of the crystalline material along specific directions. Energy frameworks of the molecular packing are displayed in Figure 9.

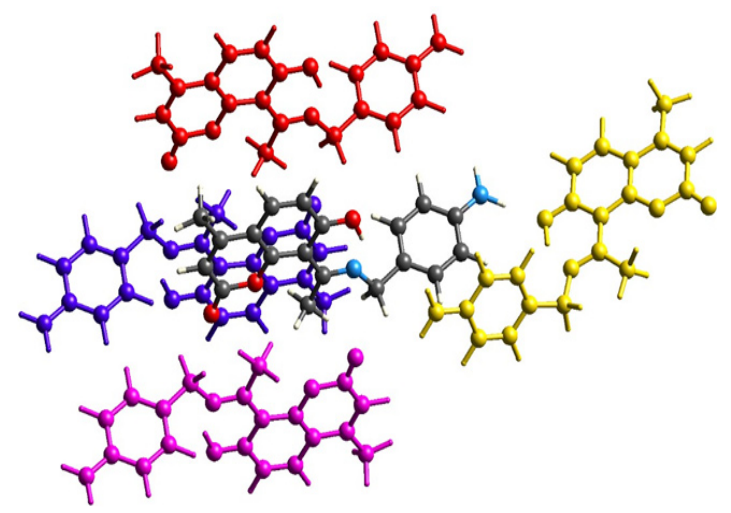

Fig. 8. Major molecular pairs of high strength intermolecular interactions of the title compound

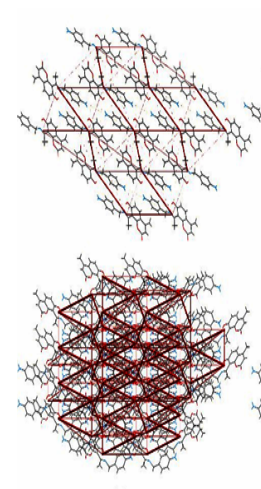

(a)

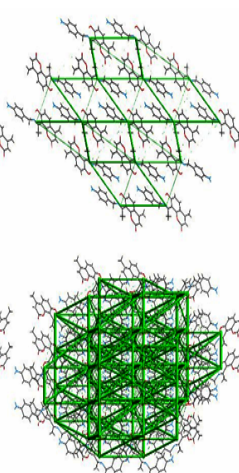

(b)
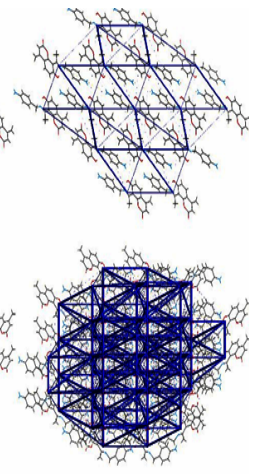

(c)

Fig. 9. Energy frameworks describing major interactionsin the molecular structure: Red- Coulomb energy;Greendispersive energy; Blue-total energy

Table 4: Interaction energy and lattice energy of the crystal packing

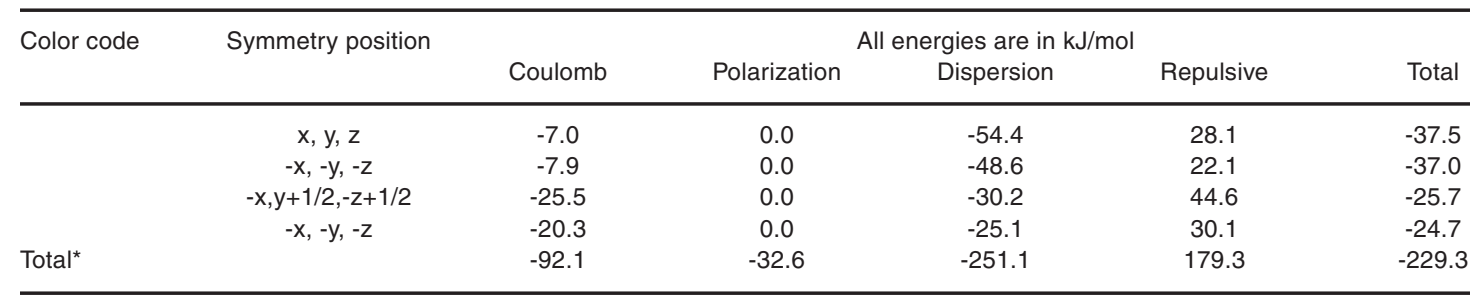

*The total energy corresponds to the total interaction energy of all molecular pairs within

the sphere of radius $20 \AA$ and hence it does not match with the actual sum of the above four rows. 


\section{DFT calculations}

Density functional theory makes use of electron density function to realize the wavefunctions of electrons and hence to quantum mechanically evaluate various physical and chemical properties of the molecule. Hence it is one of highly trusted method to theoretically investigate the structure, and allied properties of organic molecules. Gas phase optimization of coordinates was performed using DFT calculations by employing B3LYP functionals combined with $6-311+G(d, p)$ basis set. The optimized structure corresponding to the lowest energy configuration and shows high correlation with the structure obtained using X-ray diffraction studies as confirmed by high correlation coefficients. Selected structural parameters from DFT calculations are compared with XRD studies in Table 2. The molecular orbitals represent the molecular electronic wavefunctions that can be used to obtain several important properties like chemical reactivity, electronegativity and many more. The frontier molecular orbitals are the ones which dominantly control these properties. The energy gap between such frontier molecular orbitals was determined to be 3.9026 eV using DFT calculations. The global and local reactive parameters obtained from these molecular orbitals are enlisted in Table 5. Molecular electrostatic potential map was plotted to recognize the possible reactive locations of the title compound that indicates high electronegative regions near the $=\mathrm{O}$ and $-\mathrm{OH}$ moieties and high electropositive region around the $-\mathrm{NH}_{2}$ moiety as described by the red and blue colors respectively. The HOMO-LUMO and the molecular electrostatic potential map are provided in Fig. 10. Further, the electronic transitions among various molecular orbitals were evaluated with TDDFT calculations. Simulated optical absorption spectrum is provided along with the experimental spectrum in Fig. 4. Transition between the frontier molecular orbitals was observed to be weak as indicated by low oscillator strength. However, the highest absorption was observed from HOMO-1 orbital to LUMO+1 at $305.58 \mathrm{~nm}$ with an oscillator strength of 0.2217 .

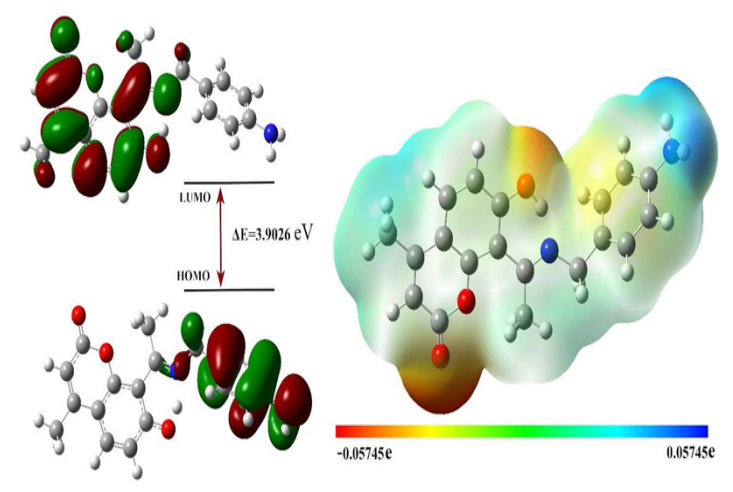

Fig. 10. HOMO-LUMO and MEP of the title molecule

Table 5: HOMO-LUMO energy values and associated properties obtained from DFT calculations

\begin{tabular}{cc}
\hline HOMO energy & $-5.4694 \mathrm{eV}$ \\
LUMO energy & $-1.5668 \mathrm{eV}$ \\
$\Delta \mathrm{E}$ & $3.9026 \mathrm{eV}$ \\
Electronegativity & $3.5181 \mathrm{eV}$ \\
Chemical Potential & $-3.5181 \mathrm{eV}$ \\
Global hardness & $1.9513 \mathrm{eV}$ \\
Global softness & $0.2562 \mathrm{eV}^{-1}$ \\
Electrophilicity & $3.1710 \mathrm{eV}$ \\
\hline
\end{tabular}

CONCLUSION

A novel coumarin derivative was synthesized through the reaction between substituted acetyl coumarin and 4-aminobenzylamine. The compound was characterized using NMR and FTIR spectroscopic techniques. The UV-Visible spectroscopy revealed that the compound exhibits no absorption in visible range but a broad absorbance peak that ranging from $280 \mathrm{~nm}$ to $300 \mathrm{~nm}$ of UV region. The absorption was found to be associated with electronic transitions from HOMO-1 to LUMO+1. Through XRD studies, the compound was found to crystallize in monoclinic crystal system. Diverse intermolecular interactions including N24-H24B...O1 and C17-H17A...O10 hydrogen bonds; $\mathrm{C} 7-\mathrm{H} 7 \mathrm{~B} \ldots \mathrm{Cg}(3)$ and $\mathrm{Cg} . . \mathrm{Cg}$ interactions were observed to enhance the crystal structure stability. These intermolecular hydrogen bonds have resulted in the formation of $R^{2}(18)$ type of supramolecular architecture and an infinite chain down the b-axis. The studies on Hirshfeld surface showed that the $\mathrm{H} . . . \mathrm{H}(42.9 \%), \mathrm{C} . . \mathrm{H}(32.7 \%)$ and O...H $(20.1 \%)$ interactions contribute for more than $95 \%$ of total interaction. The interaction energy and lattice energy calculations showed that the compound is highly stable. Further, the quantum chemical computations carried out using density functional theory confirmed that the molecular 
structure determined corresponds to the minimum energy configuration. Geometrical parameters calculated using DFT calculations displayed high correlation with the experimental values indicating that the XRD structure. Highly reactive regions were predicted to be present near $-\mathrm{OH}$ and $-\mathrm{NH}_{2}$ groups from molecular electrostatic potential map. The energy framework analysis showed that strongest intermolecular interaction was observed down the $b$-axis of the crystal.

\section{ACKNOWLEDGMENT}

This research did not receive any specific grant from funding agencies in the public, commercial, or not-for-profit sectors.

\section{Conflicts of Interest}

All the authors mention that there no conflict of interest of any kind.

\section{REFERENCES}

1. Jain, P. K.; Joshi, H. J. Appl. Pharm. Sci., 2012, 2, 236-240.

2. Arora, R. K.; Kaur, N.; Bansal, Y.; Bansal, G. Acta Pharm. Sin B., 2014, 4, 368-375.

3. Liu, L.; Hu, Y.; Shen, Y. F.; Wang, G. X.; Zhu, B. J. Antiviral Res., 2017, 144, 173-185

4. Hwu, J. R.; Singha, R.; Hong, S. C.; Chang, Y. H.; Das, A. R.; Vliegen, I.; Clercq, E. D.; Neyts, J. Antiviral Research., 2008, 77, 157-162.

5. Arshad, A.; Osman, H.; Bagley, M. C.; Lam, C. K.; Mohamad, S.; Zahariluddin, A. S. M. Eur. J. Med. Chem., 2011, 46, 3788-3794.

6. Dholariya, H. R.; Patel, K. S.; Patel, J. C.; Patel, A. K.; Patel, K. D. Med. Chem. Res., 2013, 22, 5848-5860.

7. Zhou, P.; Takaishi, Y.; Duan, H.; Chen, B.; Honda, G.; Itoh, M.; Takeda, Y.; Kodzhimatov, O. K.; Lee, K. H. Phytochemistry., 2000, 53, 689-697.

8. Shikishima, Y.; Takaishi, Y.; Honda, G.; Ito, M.; Takeda, Y.; Kodzhimatov, O. K.; Ashurmetov, O.; Lee, K. H. Chem. Pharm. Bull., 2001, 49, 877-880.

9. Huang, L.; Yuan, X.; Yu, D.; Lee, K. H.; Chen, C. H. Virology., 2005, 332, 623-628.

10. Al-Soud, Y. A.; Al-Sa'doni, H. H.; Amajaour, H. A.; Salih, K. S.; Mubarakb, M. S.; Al- Masoudic, N. A.; Z. Naturforsch. B., 2008, 63, 83-89.

11. Musa, M. A.; Cooperwood, J. S.; Khan, M. O. F. Curr. Med. Chem., 2008, 15, 2664-2679.

12. Kostova, I. Curr. Med. Chem., 2005, 5, 29-46.

13. Chen, H.; Li, S.; Yao, Y.; Zhou, L.; Zhao, J.; Gu, Y.; Li, X. Bioorg. Med. Chem. Lett., 2013, 23, 4785-4789.

14. Lacy, A.; O'kennedy, R. Curr. Pharm. Des., 2004, 10, 3797-3811.

15. Brooker, N.;Windorski, J.; Bluml, E. Commun.
Agric. Appl. Biol. Sci., 2008, 73, 81-89.

16. Zhao, L.; Zhang, J.; Liu, T.; Mou, H.; Wei, C.; Hu, D.; Song, B. J. Agric. Food Chem., 2019, 68, 975-981.

17. Kaewamatawong, T.; Lohavanijaya, A.; Charoenlertkul, P.; Srichairat, S. Thai J. Vet. Med., 2011, 41, 239.

18. Jung, H. S.; Kwon, P. S.; Lee, J. W.; Kim, J. I.; Hong, C. S.; Kim, J.W.; Yan, S.; Lee, J.Y.; Lee, J. H.; Joo, T.; Kim, J. S. J. Am. Chem. Soc., 2009, 131, 2008-2012.

19. Kwon, H.; Lee, K.; Kim, H. J. Chem. Commun., 2011, 47, 1773-1775.

20. Sun, Q.; Peng, D. Y.; Yang, S. G.; Zhu, X. L.; Yang, W. C.; Yang, G. F. Bioorg. Med. Chem. Lett., 2014, 22, 4784-4791.

21. Piazzi, L.; Cavalli, A.; Colizzi, F.; Belluti, F.; Bartolini, M.; Mancini, F.; Rampa, A. Bioorg. Med. Chem. Lett., 2008, 18, 423-426.

22. Anand, P.; Singh, B. Archives of Pharm. Res., 2013, 36, 375-399.

23. Rigaku, Crystal Clear., 2011.

24. Sheldrick, G. M. Acta Cryst. A., 1990, 46, 467-473.

25. Sheldrick, G. M. Acta Cryst. C., 2015, 71, 3-8.

26. Spek, A. L. Acta. Cryst. A., 1990, 46, 34.

27. Macrae, C. F.; Bruno, I. J.; Chisholm, J. A.; Edgington, P. R.; McCabe, P; Pidcock, E.; Rodriguez, L. M.; Taylor, R.; van de Streek, J.; Wood, P. A. J. Appl. Cryst., 2008, 41, 466- 470.

28. Wolff, S. K.; Grimwood, D. J.; McKinnon, J. J.; Turner, M. J.; Jayatilaka, D.; Spackman, M. A. Crystal Explorer (Version 3.0), Uni. West. Aust. 2012. 29. Seth, S. K. Cryst. Eng. Comm., 2013, 15, 1772-1781.

30. Seth, S. K. J. Mol. Struct., 2014, 1064, 70-75.

31. Lee, C.; Yang, W.; Parr, R. G. Phys. Rev. B., 1988, 37, 785. 
32. Becke, A. D. J. Chem. Phys., 1992, 96, 21552160.

33. Hariharan, P. C.; Pople, J. A. Theor. Chem. Acc., 1973, 28, 213-222.

34. Marques, M. A.; Gross, E. K. Annu. Rev. Phys. Chem., 2004, 55, 427-455.

35. Chethan Prathap K. N.; Lokanath N. K. J. Mol. Struct., 2018, 1171, 564-577.

36. Frisch, M. J.; Trucks, G. W.; Schlegel, H. B.; Scuseria, G. E.; Robb, M. A.; Cheeseman,J. R.; Scalmani, G.; Barone, V.; Mennucci, B.; Petersson, G. A.; Nakatsuji, H.; Caricato, M.; Li, X.; Hratchian, H. P.; Izmaylov, A. F.; Bloino, J.; Zheng, G.; Sonnenberg, J. L.; Hada, M.; Ehara, M.; Toyota, K.; Fukuda, R.; Hasegawa, J.; Ishida, M.; Nakajima, T.; Honda, Y.; Kitao, O.; Nakai, H.; Vreven, T.; Montgomery, J. A.; Peralta, J. E.; Ogliaro, F.; Bearpark, M.; Heyd,
J. J.; Brothers, E.; Kudin, K. N.; Staroverov, V. N.; Keith, T.; Kobayashi, R.; Normand, J.; Raghavachari, K.; Rendell, A.; Burant, J. C.; lyengar, S. S.; Tomasi, J.; Cossi, M.; Rega, N.; Millam, J. M.; Klene, M.; Knox, J. E.; Cross, J. B.; Bakken, V.; Adamo, C.; Jaramillo, J.; Gomperts, R.; Stratmann, R. E.; Yazyev, O.; Austin, A. J.; Cammi, R.; Pomelli, C.; Ochterski, J.W.; Martin, R. L.; Morokuma, K.; Zakrzewski, V. G.; Voth, G. A.; Salvador, P.; Dannenberg, J. J.; Dapprich, S.; Daniels, A. D.; Farkas, O.; Foresman, J. B.; Ortiz, J. V.; Cioslowski, J.; Fox, D. J. Gaussian 09, Revision B.01, Gaussian, Inc.,Wallingford-CT., 2010.

37. Frisch, A.; Dennington, R.; Keith, T.; Millam, J.; Nielsen, A.; Holder, A.; Hiscocks, J. GaussView Version 5 User Manual, Gaussian Inc., Wallingford-CT., 2009. 